\title{
ZALMOXIS ȘI PRACTICILE DE DOBÂNDIRE A NEMURIRII POTRIVIT TEXTULUI LUI HERODOT
}

\author{
Daniela-Luminiţa IVANOVICI*
}

\begin{abstract}
Zalmoxis and the immortality rituals according to Herodotus Historiae $^{1}$. The present study examines the passage from Herodotus Historiae IV, 93-96 where the Greek historian describes the Getaean god, Zalmoxis, and the practices connected with his cult. I will focus my research on two topics: the nature of Zalmoxis and the getic rituals of achieving immortality.Zalmoxis is presented as a man, as a daimon and as a god. In order to clarify this ambiguity, it is imperative to look at the Greek image of "Other", and at the projection of Thracians between the civilized Greece and a mythological North. As for the rituals regard ing immorta lity, I'll start with two rituals described by Herodotus: the sacrifice of a messenger, which was performed every five years, and thedescending of Za lmoxis into an underground chamber. This descent is assimilated with a journey in Hades, a practice connected with Greek mysteries. So, immortality was achieved in two ways: through human sacrifice, or through initiation into the mysteries discovered by Zalmoxis. Herodotus connects this initiation with Pythagora 'teachings about metempsychosis. Archaeological discoveries unfold a certain believe in the survival of the soul after death in all Thracia. The findings show that the figure of Zalmoxis is partially constructed on the Greek representation about world. The information about his doctrine of immortality is real, since it exists not only among the Getae tribe, but also a mong other Thra cian tribes.
\end{abstract}

Keywords: Zalmoxis, Herodotus, metempsychosis, Greek mysteries, human sacrifice.

"PhD Student, Faculty of Orthodox Teology at „Babeş-Boylai” University, Cluj-Napoca, Romania.

${ }^{1}$ Studiu redactat sub îndrumarea Pr. Prof. Univ. Dr. Ioan-Vasile Leb, care și-a exprimat acordul pentru publicare. 


\section{Introducere}

În studiul de față ne propunem să analizăm modul în care geții și tracii se raportau la moarte și nemurire potrivit relatării din Istoriile lui Herodot IV, 93-93. În afara textului lui Herodot, vom mai folosi ca surse autori contemporani lui sau care au trăit în perioada imediat următoare.

\section{Zalmoxis în textul lui Herodot}

Relatarea care îl descrie pe Zalmoxis se găsește în Cartea a IV-a a Istoriilor lui Herodot. Zalmoxis a rămas un exemplu de ,înțelepciune barbară" și unul dintre chipurile alterității prin intermediul căruia grecii și-au gândit propria cultură ${ }^{2}$. Herodot îi prezintă pe geți ca pe cei „,care se cred nemuritori” sau „care se fac nemuritori”, sau „practică rituri de nemurire ${ }^{3 "}$, explicând cum ating ei nemurirea. El a folosit două surse: informații culese de la geți, și informații primite de la coloniștii greci de la Hellespont și Pont. În IV, XCIV, avem expunerea primei surse, unde se relatează modul în care geţii se fac nemuritori, povestindu-se sacrificarea unui mesager o dată la patru ani $i^{4}$.

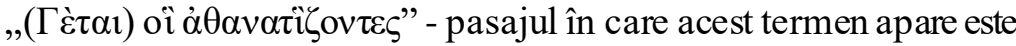
cea mai veche ocurență a cuvântului. Din modul în care Herodot îl introduce în text transpare ideea că nu l-a creat special pentru a-i descrie pe geți ${ }^{5}$, ci este folosit ca un termen familiar menit să-i ajute pe cititori să îi localizeze mai bine ${ }^{6}$. Ivan Linforth a fost primul care a propus traducerea lui prin ,a practica zeificarea" 7 . Adoptarea acestui calificativ pentru geti se leagă de faptul că la Herodot fiecare popor posedă un obicei care îl distinge față de altele ${ }^{8}$. „Oi athanatizontes” a fostmai întâi asociat cu obiceiul de a se bucura la funeralii, și nu îi desemna doar pe geți, ci și pe alte triburi

${ }^{2}$ Dan DANA, ,Occultations de Zalmoxis et occultation de l'histoire. Un aspect du dossier Mircea Eliade", în Anabases, 5 (2007), p. 11.

${ }^{3}$ Herodotus, Cele mai frumoase istorii, trad. Adelina Piatkowski și Felicia Vanț-Ștef, Bucureşti, Edit. Humanitas, 2018, p. 155.

${ }^{4}$ Ibidem, p. 156.

${ }^{5}$ François HARTOG, The mirror of Herodotus: the representation of the other in the writing of history, University of California Press, Berkeley Calif, London, 2009, p. 91.

${ }^{6}$ Ivan LinforTH, „Oi Atanatizontes”, în Classical Philology, 13, 1 (1918), p. 24.

${ }^{7}$ Ibidem, p. 27.

${ }^{8}$ F. HARTOG, The mirror of Herodotus, p. 386-387. 
învecinate, precum terizii și crobizii despre care vorbește Hecataios ${ }^{9}$. Atât la el, cât și la Herodot, „oỉ $\alpha \theta \alpha v \alpha \tau i \zeta o v \tau \varepsilon \varsigma ”$ este un epitet formular care identifică printr-o însușire specifică un popor sau o persoană ${ }^{10}$. Herodot conferă acest epitet doar geților și distribuie altor triburi tracice celelalte obiceiuri ca înmormântările vesele (trausi) sau sacrificarea soției preferate (crestoni). Hellanicos ${ }^{11}$ strânge informații despre funeraliile vesele și le asociază inițierilor pe care Zalmoxis le-a adus geților. Izvoarele literare antice trimit la un fond comun care are în centru credința în nemurire ${ }^{12}$.

Zalmoxis, în relatarea lui Herodot, este descris prima dată ca $\delta \alpha u ́ \mu \omega v$, apoi ca $\theta \varepsilon o ́ s$. În gândirea greacă $\delta \alpha i ́ \mu \omega v$ reprezenta: puterea divină, zeul; sufletele oamenilor din Vârsta de Aur care acționau ca zeităti tutelare ${ }^{13}$. In următoarea propoziție sunt oferite mai multe informații privind numele lui Zalmoxis, care este cunoscut de către traci și sub numele de Gebeleizis, arătând că, după cum Zalmoxis are cel puțin două nume, la fel poate fi un $\delta \alpha i \mu \omega v$ sau altceva ${ }^{14}$. Mai departe, în pasajul ce descrie sacrificarea mesagerului, Herodot spune că dacă el moare „ei cred că zeul $(\theta \varepsilon o ́ \varsigma)$ le este favorabil". În contrast cu intercalarea anterioară a lui $\delta \alpha i ́ \mu \omega v, \theta \varepsilon o ́ \varsigma$ nu este introdus ca o intervenție din partea autorului, care aici relatează părerea geților. Desigur că e zeul Zalmoxis. Însă, nu ne eliberăm de ambiguități terminologice, căci $\theta \varepsilon o ́ \varsigma$ se poate referi și la zei în general ${ }^{15}$.

Sacrificarea mesagerului de către geți poate fi privită ca mijlocul prin care cel sacrificat devenea nemuritor. Termenul ,sacrificiu” descrie actul de a ucide un animal sau o persoană ca ofrandă pentru o zeitate ${ }^{16}$.

${ }^{9}$ James Shotwell, The history of history, Columbia University Press, New York, 1950, p. 172-173.

${ }^{10}$ Ca de exemplu, „Ahile cel iute de picior”. Cf. Homer, Odiseea, trad. George Murnu, Bucureşti, Edit. Univers, 1971, p. 251.

${ }^{11}$ Vladimir ILIESCU et alii (eds.), Izvoarele istoriei României. I. De la Hesiod la Itinerarul lui Antoninus, vol. I, Bucureşti, Edit. Academiei Republicii Populare Române, 1964, p. 21.

12 Zoe Petre, Practica nemuririi : o lectură critică a izvoarelor greceşti referitoare la geţi, Iaşi, Edit. Polirom, 2004, p. 61.

${ }^{13}$ Malcolm ScHOFIELD, „Heraclitus Theory of Soul and its Antecedents”, în Companions to ancient thought. Psychology, vol. 2, Cambridge University Press, Cambridge, 1991, p. 32.

${ }^{14}$ F. HARTOG, The mirror of Herodotus, p. 87.

15 Ibidem, p. 87.

${ }^{16}$ David CARRASCO, „Sacrifice/Human sacrifice in religious traditions”, în The Oxford handbook of Religion and Violence, Mark JUERGENSMEYER et alii (eds.), Oxford University Press, USA, 2013, p. 210. 
Sacrificiile umane erau făcute pentru restaurarea autorității și revitalizarea bunăstării orașelor. Ele mai pot apărea și în cadrul cultului ritual din jurul regelui și aristocrației, a căror putere în acestă lume și soartă în lumea de dincolo depindeau de uciderea altor oameni ${ }^{17}$. Moartea sacrificatului, sângele și trupul său, reprezentau plata oferită pentru rezolvarea problemei celui care aduceajertfa. Ideea care se desprinde este aceea a pierderii, care asigura sprijinul zeului și îl mulțumea ${ }^{18}$. Uneori, vorbim și de o substituire care are loc. Zeii sunt cei care îl înlocuiesc pe cel adus spre sacrificare, care se golește de identitatea sa umană și se umple de spiritul divinității ce suferă în locul lui. Rezultatul era o nouă naştere pentru zeul care fusese ucis, el reapărând în substanța vitală ce intră în compoziția plantelor, animalelor, stelelor și, uneori, a regilor ${ }^{19}$. Supraviețuirea mesagerului putea să fie pentru geți semnul că Zalmoxis nu 1-a considerat demn pe cel adus ca să fie locuit de el și să devină astfel nemuritor. În sacrificarea mesagerului se poate vedea o tentativă de reactualizare a contactului inițiaţilor cu divinitatea, pentru a se reveni la starea originară de comuniune pe care au avut-o cândva cu Zalmoxis ${ }^{20}$.

A doua sursă de informații a lui Herodot o reprezintă coloniștii din coloniile grecești din Pontul Euxin, care mărturisesc că Zalmoxis a fost sclav al lui Pitagora din Samos, iar după eliberare a revenit în sânul geţilor, pe care i-a înşelat că e zeu şi că vor deveni nemuritori ${ }^{21}$. Primul lucru pe care îl observăm în acest text este că pentru coloniștii greci Zalmoxis e doar $\alpha ̋ v \theta \rho \omega \pi o s$. Taufer socotea că aici principala problemă e legată de identitatea divină sau umană a lui Zalmoxis, ipoteza ponticilor încercând raționalizarea și demitizarea zeului get ${ }^{22}$. Relatarea despe sclavia lui Zalmoxis nu ne spune adevărul despre geți, însă ne arată ce credeau grecii despre ei. Ei îi socoteau înapoiați intelectual și de aceea au putut crede povestea nemuririi spusă de Zalmoxis ${ }^{23}$. Pentru acești greci, Zalmoxis este un șarlatan, nici măcar un $\delta \alpha i ́ \mu \omega v$. În scrierile antice

${ }^{17}$ Ibidem, p. 214.

${ }^{18}$ A. Nour, Cultul lui Zalmoxis, Bucureşti, Tipogr. Cărţilor Bisericeşti, 1941, p. 55.

${ }^{19}$ D. CARRASCO, ,Sacrifice/Human sacrifice in religious traditions”, p. 213.

${ }^{20}$ Matteo TAUfER, „Zalmoxis nella tradizione greca: rassegna e rilettura delle fonti”, în Quaderni di storia. (2008), p. 150.

${ }^{21}$ Herodotus, Cele mai frumoase istorii, p. 157.

${ }^{22}$ M. TAufER, ,Zalmoxis nella tradizione greca”, p. 140.

${ }^{23}$ I. Linforth, „Oi Atanatizontes”, p. 30. 
grecești, tracii posedau toate „,calitățile” barbarilor: erau războinici însetați de sânge, aliați nesiguri, imorali, cu comportament sexual deviant și bețivi feroce. Mai mult, ei nu posedau prea multă inteligență. Aristotel amintește de membrii unui trib trac care știau să numere doar până la patru. Paralel însă cu această imagine negativă a tracilor, avem și o viziune total opusă: zei cu origini tracice, grupări asceticecare se abțineau de la carne și relații intime ${ }^{24}$. Evoluția $\delta \alpha i ́ \mu \omega v-\theta \varepsilon o ́ \varsigma$ - ă $v \theta \rho \omega \pi$ o exprimă ambiguitatea identității lui Zalmoxis. Această ambiguitate nu este deloc întâmplătoare, fiind asemănătoare celei de care e înconjurat și Pitagora ${ }^{25}$.

Mircea Eliade se îndepărtează de imaginea lui Zalmoxis ca șarlatan, și ia doar informațiile care indică asemănarea dintre ZalmoxisPitagora și prezența unei doctrine ce presupunea ritualuri de iniţiere, în urma cărora era asigurată nemurirea participanților. Andreonul construit de Zalmoxis pentru a-i ospăta pe fruntaşii geți e asemănat de Eliade cu sala lui Pitagora din Crotona, unde acesta predica, sau cu camerele asociațiilor religioase secrete în care aveau loc banchete rituale ${ }^{26}$. „Postexistența fericită” pe care Zalmoxis a predicat-o invitaților săi nu era una generală, ci se obținea în urma unei iniţieri ${ }^{27}$, fiindcă ea îi cuprindea pe oaspeții lui și pe urmașii acestora. Printre traci existau trei credințe privind postexistența sufletului. Hellanikos relatează despre două triburi tracice, terizii și crobizii, că îmbrățișau credința că morții nu mor, ci merg la Zalmoxis, iar după o vreme se vor întoarce. De aceea, la moartea cuiva ei se bucurau și aduceau ofrande pentru ca „mortul să revină" ${ }^{28}$. Pomponius Mela mai amintește două credințe: că sufletele nu vor reveni, dar se vor bucura de o existență fericită, și că sufletele mor, dar că este mai preferabil să mori decât să trăiești ${ }^{29}$.

${ }^{24}$ Tchavdar MARINOV, „Ancient Thrace in the Modern Imagination: Ideological Aspects of the Construction of Thracian Studies in Southeast Europe (Romania, Greece, Bulgaria)", în Entangled Histories of the Balkans, Roumen DASKALOV, Alexander VEZENKOV (eds.), vol. III, Brill, 2015, p. 14-15.

${ }^{25}$ F. HARTOG, The mirror of Herodotus, p. 87.

${ }^{26}$ Mircea Eliade, De la Zalmoxis la Genghis-Han:studii comparative despre religiile şi folclorul Daciei şi Europei orientale, Bucureşti, Edit. Humanitas, 1995, p. 34.

${ }^{27}$ Ibidem, p. 40.

${ }^{28}$ V. ILIESCU et alii (eds.), Izvoarele istoriei României. I. De la Hesiod la Itinerarul lui Antoninus, vol. I, p. 21.

${ }^{29}$ Ibidem, p. 389. 
Erwin Rohde înțelege prin „întoarcerea morților”, credința în reîncarnare, învățătură pe care Pitagora a dezvoltat-o. În privința sufletului, Pitagora profesează ideea existenței unui suflet universal din care își iau ființa zeii prin emanație. Oamenii se află pe ultima treaptă a scării emanațiilor, ei având valoare doar ca suflet, trupul fiind o formă trecătoare. Acest suflet este un număr izvorât din divinitate care, înainte de a atinge fericirea, trece printr-o infinitate de cicluri de revenire în sufletul universal și reîntoarcere în lume $(\mu \varepsilon \tau \varepsilon \mu \psi v i \chi \omega \sigma \zeta)^{30}$, ei putând să se reîncarneze în plante sau animale. Însă, în ceea ce îi privește pe traci și revenirea morților, vedem din sursele antice amintite mai sus că ei nu credeau că aceștia se vor întoarce într-o altă formă decât cea avută înainte de moarte ${ }^{31}$.

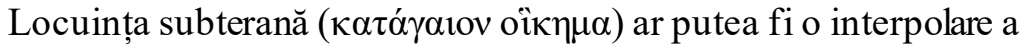
lui Herodot, care amintește de o legendă ce circula despre Pitagora ${ }^{32}$. Potrivit lui Eliade, retragerea într-o ascunzătoare sau coborârea într-o cameră subterană sunt echivalente simbolic cu o katabasis, cu un descensus ad inferos întreprins în vederea unei inițieri ${ }^{33}$. Legenda despre coborârea lui Pitagora în Lumea Morților e amintită în sec. III î. Hr. de Hieronimos din Rhodos ${ }^{34}$ și Hermippos din Smirna ${ }^{35}$ : Pitagora construiește o cameră subterană unde trăiește câțiva ani. În această perioadă, mama lui îi aducea veștile din cetate astfel că, atunci când revine, slab, tras la față și știind tot ce s-a petrecut în anii absenței lui, cei din cetate cred cu adevărat că a călătorit în Hades, a intrat în posesia unor taine privind viața de dincolo și a devenit divin ${ }^{36}$. Coborârea în lumea morților și întoarcerea în lumea celor vii erau necesare pentru biruirea morții, secretele supraviețuirii dincolo putând fi descoperiteși împărtășite

${ }^{30}$ A. Nour, Cultul lui Zalmoxis, p. 24-25.

${ }^{31}$ M. Eliade, De la Zalmoxis la Genghis-Han, p. 41.

${ }^{32}$ Ibidem, p. 34.

${ }^{33}$ Ibidem, p. 35.

34 William Wall Fortenbaugh, Stephen Augustus White, Lyco and Traos and Hieronymus of Rhodes: Text, Translation, and Discussion, coll. Rutgers University Studies in Classical Humanities 12, Transaction Publishers, 2004, p. 203.

35 Joseph Bidez, Les mages hellénisés: Zoroastre, Ostanès et Hystaspe d'après la tradition grecque., vol. 1, Paris, 1938, p. 85-88.

${ }^{36}$ Kitty Ferguson, The Music of Pythagoras: How an Ancient Brotherhood Cracked the Code of the Universe and Lit the Path from Antiquity to Outer Space, Walker Books, New York, 2011, p. 60. 
celor care urmau reguli stricte. Acest fapt e observabil în misterele lui Dyonisos $^{37}$ şi Orfeu ${ }^{38}$. Mântuirea presupunea un proces de purificare a trupului, urmată de inițierea în mistere, care oferea inițiatului înțelepciune pentru a o folosi ca parolă și hartă în Hades. Inițiatul intra într-o frăție mistică și spera ca după moarte să nu devină una dintre umbrele rătăcitoare prin Hades, ci să se bucure de o existență eternă în Insula Fericiților. Pe cei neinițiați îi aștepta o serie de reîncarnări sub formă umană și animală $\breve{~}^{39}$.

\section{Lumea tracă şi credinţa în nemurire}

Yulia Ustinova vorbește despre un alt tip de nemurire care se întâlnește în lumea tracă: continuarea vieții pe pământ sub formă de

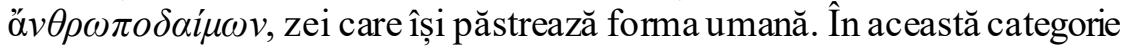
ea îi amintește pe: Amphiaraos ${ }^{40}$, Trophonios $^{41}$, Asclepios ${ }^{42}$, Kaineus ${ }^{43}$, Aristaios $^{44}$, Zalmoxis și Rhesos ${ }^{45}$. Toți au în comun coborârea sub pământ ( $\alpha \tau \tau \dot{\alpha} \beta \alpha \sigma l \varsigma)$, caracterul de $\delta \alpha i \mu \omega v^{46}$ și modul excepțional de existență: fiind încă în viață, se coboară sub pământ și își continuă implicarea în viața muritorilor, rămânând invizibili acestora. Statutul acestor semizei este neobişnuit, căci ei nu mai părăsesc locul unde pământul i-a înghițit, dar nu mai apar pe tărâmul celor vii decât prin vis sau revelaţie, ei neaparținând nici tărâmului morților, nici tărâmului viilor, nici tărâmului zeilor. De aceea, ei pot să se manifeste ca mediatori între aceste lumi.

${ }^{37}$ Nicola Mureddu, „A Dark Dionysus: The transformation of a Greek god between the Bronze and Iron Age", în Rosetta, 22 (2018), p. 94.

38 Yidy Paez CASAdiegos, „Orpheus or the Soteriological Reform of the Dionysian Mysteries", în American Journal of Sociological Research, 2, 3 (2012), p. 40.

${ }^{39}$ Ibidem, p. 43.

${ }^{40}$ Christos Iavazzo, „Amphiaraos of Attica: The «Second Asclepius»”, în Vesalius, 18, 1 (2012), p. 45-46.

${ }^{41}$ Yulia UstinovA, ,«Either a Daimon, or a Hero, or Perhaps a God:» Mythical Residents of Subterranean Chambers", în Kernos, 15 (2002), p. 272-273.

42 Touraj NAYERnOURI, „Asclepius, Caduceus, and Simurgh as Medical Symbols Part I”, în Archives of Iranian Medicine, 13, 1 (2010), p. 62.

${ }^{43}$ M. CARY et alii (eds.), „The Oxford Classical Dictionary”, p. 152.

${ }^{44}$ Ibidem, p. 89.

${ }^{45}$ Ibidem, p. 766.

46 Yulia Ustinova, ,Either a Daimon, or a Hero, or Perhaps a God: Mythical Residents of Subterranean Chambers", p. 287. 
Sanctuarele lui Amphiaraos și Trophonios se aflau în vecinătatea cetăților lor, iar Zalmoxis și Rhesos, trăind în munții lor sacrii, erau socotiți patroni ai unor triburi tracice. De aceea, fiecare dintre ei era stăpânul pământului în care își găsiseră atât sfârșitul, cât și nemurirea ${ }^{47}$.

În Tracia, mormântul era socotit locuința decedatului, căci forma mormintelor seamănă cu cea a caselor, ele fiind aranjate cu numeroase obiecte casnice. $\mathrm{O}$ atenție specială era acordată vestimentației. Uneori vestimentația era întregită de obiecte de natură ceremonială, care erau considerate însemne ale puterii sau simboluri ale nemuririi. Prezenta centurilor ca obiecte vestimentare ar putea avea și un înțeles simbolic. În multe culturi, centura este asociată cu puterea sau cu o anumită poziție, iar procesul punerii unei centuri era socotit ca o pregătire pentru o călătorie de lungă durată. Nu în ultimul rând, centura formează un cerc magic în jurul trupului celui decedat, separându-l de cei vii și protejându1 de forțele răului ${ }^{48}$.

Tracii ofereau un sacrificiu adițional la locul înmormântării. Cai și câini erau uciși ritual și erau îngropaţi aproape de locul înhumării sau împreună cu cel decedat. Acest sacrificiu este pus în legătură cu rolurile animalelor ca mediatori între lumea celor vii și a celor morți, fiind socotite și simboluri ale puterii și nemuririi. Lamentațiile funerare erau considerate obligatorii, ele fiind și un prilej de a relata în cuvinte și cânt ceva despre trecutul celui decedat și despre viața de dincolo care îl aștepta ${ }^{49}$. Existența credinței că cel mort își va continua viața în tumulul în care a fost înhumat pare a fi demonstrată de faptul că acesta era așezat pe un pat, ca la banchet, și nu îngropat; exista un cult de cinstire al morților mult după deces, după cum se vede din rămășițele de ofrande și altare descoperite lângă tumuli; ridicarea tumulilor într-un mediu natural,

\footnotetext{
${ }^{47}$ Ibidem, p. 286-287.

48 Roumyana Georgieva, „Burial rites in Thrace and Phrygia”, în Thracians and Phrygians: Problems of Parallelism. Proceedings of an International Symposium on the Archaeology, History and Ancient Languages of Thrace and Phrygia. Ankara, 3-4 June 1995, Numan TunA et alii (eds.), METU, Faculty of Architecture Press, Ankara, 1995 , p. 62.

${ }^{49}$ Ibidem, p. 63.
} 
departe de așezările locuite, pentru ca cel mort să își continue noua existență departe de amestecul celor vii ${ }^{50}$.

\section{Concluzii}

Primul aspect uşor observabil privindu-l pe Zalmoxis este inexistența unui izvor get, scris sau arheologic, care să ne prezinte natura acestui zeu. Descrierea lui ca $\delta \alpha i ́ \mu \omega v-\theta \varepsilon o ́ \varsigma-\not \partial v \theta \rho \omega \pi o \varsigma$ de către Herodot dovedește nesiguranța istoricului în privința caracterului acestuia. Partea cea mai consistentă a textului său e reprezentată de mărturia grecilor pontici care își prezintă propria versiune asupra originii zeului Zalmoxis, imaginea lui ca sclav al lui Pitagora având rolul de a evidenţia distanța dintre „înțelepciunea” barbară și cea greacă. Chiar Herodot se îndoiește de veridicitatea poveștii, socotind că Zalmoxis a trăit cu mult înainte de filosoful grec ${ }^{51}$. Informaţia privind sacrificarea mesagerului cel mai probabil provine direct de la geți; acest ritual e văzut de mulți cercetători, precum Mircea Eliade, Ivan Linforth sau F. Hartog, atât ca o modalitate prin care cel jertfit devenea nemuritor, dar și ca mijloc de redobândire a comuniunii cu zeul. Conexiunile pe care Mircea Eliade le face cu misterele grecești dionisiace sau orfice, rămân doar teorii care nu pot fi nici confirmate, nici infirmate în lipsa unui izvor sigur. Singura certitudine în privința religiei geto-dacilor este existența credinței în supraviețuirea sufletului după moarte, însă nu știm cum anume se dobândea nemurirea și dacă era rezervată tuturor sau doar elitei. Aceeași credință se întâlnește și la celelalte triburi tracice, după cum o demonstrează cercetarea tumulilor și a ritualurilor funerare, ceea ce înseamnă că Zalmoxis a fost răspândit pe o arie geografică mai vastă, în întreaga Tracie.

\section{Referinţe bibliografice:}

1. BIDEZ, Joseph, Les mages hellénisés: Zoroastre, Ostanès et Hystaspe d'après la tradition grecque., vol. 1, Paris, 1938;.

${ }^{50}$ Kostadin Rabadjiev, ,The Thracian tomb as ritual space of the Beyond (Plates 110128)", în Tumulus as Sema. Space, Politics, Culture and Religion in the First Millennium BC., vol. 27, coll. Topoi. Berlin Studies of the Ancient World, Walter de Gruyter, Berlin/Boston, 2016, p. 282-291.

${ }^{51}$ Herodotus, Cele mai frumoase istorii, p. 205. 
2. CARRASCO, David, „Sa crifice/Human sacrifice in religious traditions”, în Mark Juergensmeyer, Margo Kitts, Michael Jerryson (eds.), The Oxford handbook of Religion and Violence, Oxford University Press, USA, 2013, p. 209-225;

3. CASADIEGOS, Yidy Paez, „Orpheus or the Soteriological Reform of the Dionysian Mysteries", în American Journal of Sociological Research, 2, 3 (2012), p. 38-51;

4. DANA, Dan, „Occultations de Zalmoxis et occultation de l'histoire. Un a spect du dossier Mircea Eliade", în Anabases, 5 (2007), p. 11-25;

5. ELIADE, Mircea, Istoria credințelor și ideilor religioase, Bucureşti, Edit. Științifică, 1992;

6. EliADE, Mircea, De la Zalmoxis la Genghis-Han:studii comparative despre religiile şi folclorul Daciei şi Europei orientale, Bucureşti, Edit. Humanitas, 1995;

7. Ferguson, Kitty, The Music of Pythagoras: How an Ancient Brotherhood Cracked the Code of the Universe and Lit the Path from Antiquity to Outer Space, Walker Books, New York, 2011;

8. Fortenbaugh, William Wall, White, Stephen Augustus, Lyco and Tra os and Hieronymus of Rhodes: Text, Translation, and Discussion, coll. Rutgers University Studies in Classical Humanities 12, Transaction Publishers, 2004;

9. HARTOG, François, The mirror of Herodotus: the representation of the other in the writing of history, University of California Press, Berkeley. Calif. London, 2009;

10. Herodotus, Cele mai frumoase istorii, trad. Adelina Piatkowski și Felicia Vanț-Ștef, Bucureşti, Edit. Humanitas, 2018;

11. HOMER, Odiseea, trad. George Murnu, Bucureşti, Edit. Univers, 1971;

12. IAVAZZO, Christos, „Amphiara os of Attica: The «Second Asclepius»”, în Vesalius, 18, 1 (2012),

13. ILIESCU, Vladimir et alii (eds.), Izvoarele istoriei României. I. De la Hesiod la Itinerarul lui Antoninus, vol. I, Bucureşti, Edit. Academiei Republicii Populare Române, 1964;

14. LINFORTH, Ivan, „Oi Atanatizontes”, în Classical Philology, 13, 1 (1918), p. 23-33;

15. MUREDDU, Nicola, „A Dark Dionysus: The transformation of a Greek god between the Bronze and Iron Age", în Rosetta, 22 (2018); 
16. NAYERNOURI, Touraj, „Asclepius, Caduceus, and Simurgh as Medical Symbols Part I", în Archives of Iranian Medicine , 13, 1 (2010);

17. RABADJIEV, Kostadin, „The Thra cian tomb a ritual space of the Beyond (Plates 110-128)", în: Sema. Space, Politics, Culture and Religion in the First Millennium BC. (Topoi. Berlin Studies of the Ancient World), vol. 27, Walter de Gruyter, Berlin/Boston, 2016;

18. MARINOV, Tchavdar, „Ancient Thrace in the Modern Imagination: Ideological Aspects of the Construction of Thracian Studies in Southeast Europe (Romania, Greece, Bulgaria)", în Roumen Daskalov, Alexander Vezenkov (eds.), Entangled Histories of the Balkans, vol. III, Brill, 2015;

19. Nour, Andrei, Cultul lui Zalmoxis, București, Tipogr. Cărţilor Bisericeşti, 1941;

20. Petre, Zoe, Practica nemuririi: o lectură critică a izvoarelor grecești referitoare la geți, Iași, Edit. Polirom, 2004;

21. SCHOFIELD, Malcolm, „Heraclitus Theory of Soul and its Antecedents”, în Companions to ancient thought. Psychology, vol. 2, Cambridge University Press, Cambridge, 1991;

22. SHOTwell, James, The history of history, Columbia University Press, New York, 1950;

23. TAUFER, Matteo, „Zalmoxis nella tradizione greca: rassegna e rilettura delle fonti", în Quaderni di storia. (2008);

24.Ustinova, Yulia, „«Either a Daimon, or a Hero, or Perhaps a God» Mythical Residents of Subterranean Chambers", în Kernos, 15 (2002), p. 267-288. 